Images du travail, travail des images

$4 \mid 2017$

La relation soignants/soignés à l'épreuve de l'image

\title{
Une consultation dans un cabinet d'acupuncture
}

Frédéric Obringer

\section{CpenEdition}

Journals

Édition électronique

URL : http://journals.openedition.org/itti/1037

DOI : 10.4000/itti.1037

Éditeur

Université de Poitiers

Référence électronique

Frédéric Obringer, « Une consultation dans un cabinet d'acupuncture », Images du travail, travail des images [En ligne], 4 | 2017, mis en ligne le 01 septembre 2017, consulté le 14 avril 2021. URL : http:// journals.openedition.org/itti/1037 ; DOI : https://doi.org/10.4000/itti.1037

Ce document a été généré automatiquement le 14 avril 2021.

Images du travail, travail des images 


\section{Une consultation dans un cabinet d'acupuncture}

\section{Frédéric Obringer}

Consultation d'acupuncture, Bâle, avril 2015

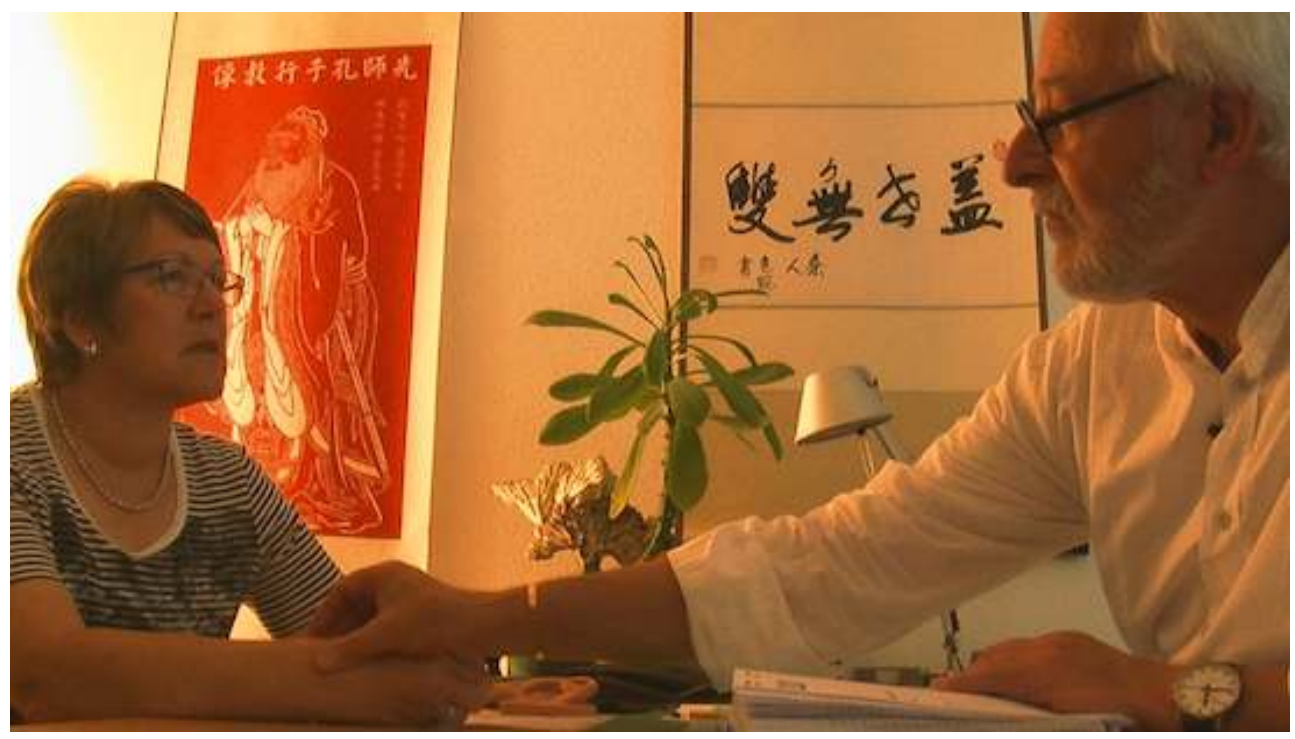

(c) G. Remillet

1 La photo a été prise en 2015 en Suisse lors d'une enquête anthropologique utilisant les images comme outil de recherche ${ }^{1}$. Le travail concernait la pratique de la médecine chinoise.

Deux personnages, une femme et un homme, sont assis face à face, séparés par un bureau. L'homme tient avec la main droite le poignet droit de la femme. On aperçoit sur le bureau un moulage d'oreille, ainsi qu'un objet décoratif représentant deux feuilles de ginkgo stylisées. Au mur sont accrochées une calligraphie chinoise et la reproduction d'un estampage, portrait en pied d'un homme âgé. 
3 Le geste effectué par le personnage de droite nous montre que c'est un praticien de médecine chinoise en train de prendre les pouls, l'une des méthodes de diagnostic. La palpation s'effectue à trois emplacements de l'artère radiale; index, majeur et annulaire sont placés sur chacun, et l'on palpe avec différentes pressions. Les informations données permettent de repérer la maladie en reconnaissant un type de pouls.

4 Le moulage de l'oreille, que l'on aperçoit sous le bras du praticien, nous renseigne sur une spécialisation de ce dernier, l'auriculothérapie ; cette discipline trouve son origine non en Chine mais en France, où elle a été développée par le Dr Paul Nogier au cours des années 1950 (Nguyen, 1989, 16), avec de nombreux points auriculaires à puncturer en considérant l'oreille comme un microcosme.

5 Le ginkgo (Ginkgo biloba L.), un grand arbre aux feuilles bilobées, a été introduit de Chine en Europe au XVIIIe s.; il est vite devenu, par son aspect exotique et le graphisme unique de son feuillage, symbole de l'Extrême-Orient.

6 Enfin, les deux illustrations décorant le mur du cabinet apportent une atmosphère de « haute culture » chinoise. Alors que la plupart des cabinets de praticiens de médecine chinoise en Europe affichent sur leurs murs des schémas d'acupuncture ou des images liées au Yin et au Yang, ou aux cinq agents, le médecin a choisi d'évoquer la culture classique de l'Empire du milieu avec un portrait représentant Confucius (Cheng, 1991, 61). Les gros caractères situés en haut du portrait sont les suivants :

7 Xianshi Kongzi xing jiao xiang 先師孔子行教像 (Portrait de Confucius en train d'enseigner)

8 Enfin, sur la calligraphie accrochée à droite, l'expression en quatre caractères que l'on peut lire, gai shi wu shuang 蓋世無雙, est une belle publicité pour le praticien; elle signifie « un être hors de pair »...

9 L'ensemble de la photographie apparait donc d'une extrême richesse sémantique. Deux éléments de l'image rejoignent les intérêts des savants et des missionnaires européens lors de la première grande rencontre de la Chine et de l'Europe, aux XVIIe et XVIIIe $s$. (Obringer, 2001). Mais l'image évoque aussi la circulation et la globalisation contemporaines des pratiques et des savoirs médicaux : à preuve ce médecin suisse prenant les pouls à la chinoise et spécialiste d'un traitement thérapeutique, l'auriculothérapie, adossé sur un corpus savant chinois mais développé en Europe.

\section{BIBLIOGRAPHIE}

Cheng A. (1997), Histoire de la pensée chinoise, Paris, Éd. du Seuil.

Nguyen J. (1989), « Auriculopuncture », in Encyclopédie des médecines naturelles, Paris, Éd.

techniques, II. 2, 12 . 
Obringer F. (2001), « Savez-vous tâter le pouls à la mode des Chinois? L'introduction de la médecine chinoise en France du XVII ${ }^{\mathrm{e}}$ siècle au XXe siècle », in Paul U. Unschuld (dir.), Médecines chinoises, Montpellier, Indigène éditions, p. 120-131.

\section{NOTES}

1. Cette recherche est menée par Lucia Candelise, Gilles Remillet et Matthias Sohr dans le cadre du projet FNS 100017_146539/1 « Les pratiques médicales chinoises en Europe. Leur réception en Suisse pour un regard comparé avec le contexte médical français et italien », 2013-2016.

\section{AUTEUR \\ FRÉDÉRIC OBRINGER}

Frédéric Obringer (CNRS) est directeur de l'UMR Chine, Corée, Japon (EHESS-CNRS, Paris). Ses thèmes de recherche sont l'histoire de la médecine en Chine et des relations médicales entre la Chine et l'Europe, ainsi que l'histoire anthropologique de l'utilisation en Chine de certaines catégories de produits naturels (médicaments, substances aromatiques et parfums, poisons). Il a notamment publié :

- L'aconit et l'orpiment. Drogues et poisons en Chine ancienne et médiévale, Paris, Fayard, 1997, 329 p. - Fengshui, l'art d'habiter la terre. Une poétique de l'espace et du temps, $2^{\mathrm{e}}$ édition corrigée, Arles, Éditions Philippe Picquier, 2009, 126 p. 